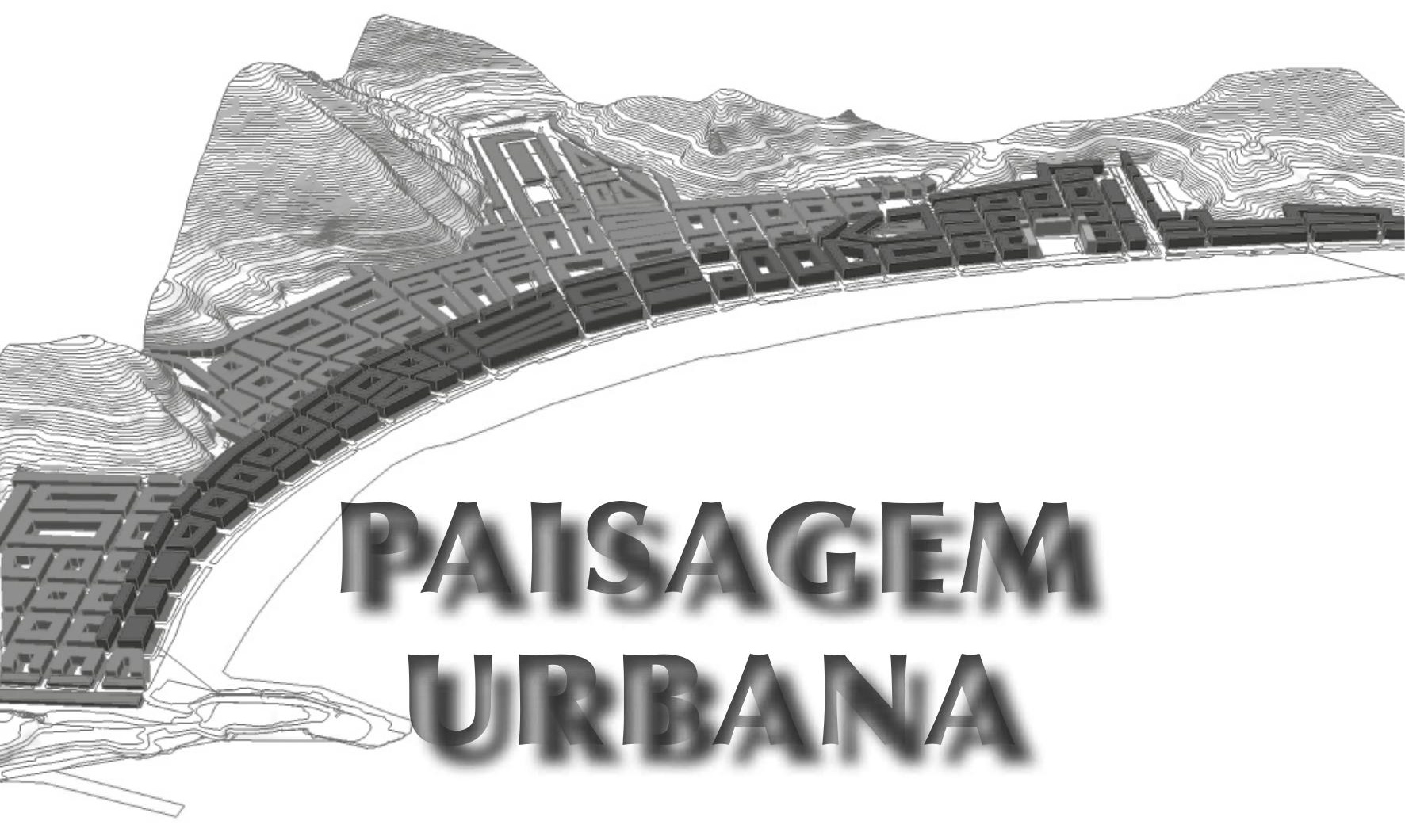




\title{
AS ÁREAS COLETIVAS DE COPACABANA: FORMAÇÃO E APROPRIAÇÃO
}

\author{
THE COMMUNAL AREAS OF COPACABANA NEIGHBORHOOD: \\ IT FORMATION AND APPROPRIATION
}

\author{
Rogerio Goldfeld Cardeman \\ Arquiteto, mestre e pesquisador do Grupo SEL-RJ do PROARQ-FAU-UFRJ \\ e-mail: r.cardeman@gmail.com
}

\begin{abstract}
RESUMO
Este artigo trata sobre os espaços livres intraquadras do bairro de Copacabana no Rio de Janeiro, denominados de áreas coletivas. Implantados na década de 1940, tornaram-se um marco do desenho urbano do bairro, sendo, mesmo assim, desconhecido pela maioria das pessoas. Neste artigo discorrerei sobre esses espaços, sua formação e apropriação, destacando sua importância como elemento de qualidade do bairro. Este trabalho é parte da pesquisa realizada quando da realização do curso de mestrado, desenvolvido no Programa de Pós-Graduação em Arquitetura do PROARQ-FAU-UFRJ, e com dissertação defendida em 2010.
\end{abstract}

\section{Palavras-chave: Copacabana, Rio de Janeiro, espaços livres, áreas coletivas.}

\section{ABSTRACT}

This article discusses the Intra-blocks open spaces of Copacabana neighborhood in Rio de Janeiro, described as Communal areas. Deployed in 1940, it became a landmark of the urban design in this neighborhood, although still unknown by most people. This article will talk about these spaces, its formation and its appropriation, highlighting its importance as an element of quality of the neighborhood. This work is part of the research done during the master program, developed at PROARQ-FAU-UFRJ Graduate Program in Architecture, with thesis dissertation defended in 2010.

Key words: Copacabana, Rio de Janeiro, open spaces, communal áreas.

\section{INTRODUÇÃO}

Neste artigo tratarei da questão dos espaços livres privados intraquadras de Copacabana, conhecidos por sua denominação legal como áreas coletivas, destacando a questão da formação e da apropriação dos espaços livres do bairro que tiveram uma abordagem mais ampla em minha dissertação de mestrado?.

Em termos de material de pesquisa e método de trabalho, analisei, primeiramente, o histórico da legislação urbanística aplicada ao bairro, a partir das leituras dos autores (AGACHE, 1930), (DOXIADIS, 1965), (ABREU, 2008) e (CARDEMAN; CARDEMAN, 2004), permitindo traçar a evolução do traçado urbano e das quadras desde a introdução das áreas coletivas até a data de término da pesquisa. Com os levantamentos de campo, que incluíram o perfil de gabarito dos edifícios, os usos e as tipologias edilícias, foi possível elaborar a maquete eletrônica e fotografias em diversos níveis, 
permitindo mapear a situação atual dos espaços livres intraquadras, suas utilizações e apropriações. Utilizei como referência os autores Tangari (1999), Macedo (1987), Ashihara (1981) e Lamas (2007), para estabelecer uma proposição de análise dos elementos levantados em campo.

Além desses instrumentos, as entrevistas informais com moradores mostraram que, apesar do que se tem como imaginário do bairro, uma área muito densa, tanto na questão edilícia como demográfica, a população residente não pensa em mudar-se do bairro, principalmente os que têm suas unidades voltadas para as áreas coletivas.

Neste artigo abordarei parte de minha pesquisa e focarei somente nesse sistema de espaços, tão instigante e rico em sua diversidade e sobre o qual pouco se sabe. Com isso espero apresentá-lo aos pesquisadores e colocá-lo no foco de uma discussão atual dos Grupos de Pesquisa em Sistemas de Espaços Livres que atuam em nível nacional.

\section{COMO SURGIRAM AS ÁREAS COLETIVAS}

Na década de 1940 alguns bairros da cidade do Rio de Janeiro já extrapolavam, conforme permitido por leis específicas, os parâmetros urbanísticos que vigoravam na maior parte da cidade (CARDEMAN, 2004). Em bairros como Copacabana, Flamengo e Catete, os novos edifícios eram construídos com dez pavimentos sem afastamentos laterais, ou seja, colados às divisas, formando, assim, um cinturão edificado no perímetro das quadras. Nessa época não existiam parâmetros como densidades máximas para as novas edificações, e as projeções horizontais podiam se estender por todo o lote, somente deixando prismas de ventilação para as partes internas das unidades, o que permitia que as edificações ficassem próximas umas das outras.

Com base na proposta de Alfred Agache em 1930 para criação de quadras com áreas internas na área central da cidade (AGACHE, 1930), os engenheiros do então Distrito Federal, como forma de assegurar algum tipo de qualidade ambiental ao conjunto de edifícios dessas quadras, criaram a Planta de Zoneamento de 1946 (Figuras 1 e 2). No caso de Copacabana, essa planta determinava um limite de profundidade para as novas edificações e variava de 23 a 30 metros, dependendo da largura da quadra. Com isso, à medida que foram sendo construídas novas edificações, respeitando esse novo alinhamento interno no miolo das quadras, foram sendo criados espaços livres que garantiram condições aceitáveis de iluminação e aeração (REIS, 2008).

Nessa planta também se determinou o número de pavimentos permitido para as novas edificações e a variarem de quatro a 12 pavimentos, e, na maioria das quadras, o gabarito permitido seria de dez pavimentos, o qual já era adotado antes de essa planta ser aprovada. Esse parâmetro foi alterado em 1958, acrescentando mais dois pavimentos às áreas, passando, assim, a maioria das quadras, a ter gabarito máximo de 12 pavimentos.

É importante destacar que essa proposta foi feita sobre uma malha urbana existente e resultante dos primeiros loteamentos do bairro feitos no final do século 19. Esses loteamentos eram destinados a residências unifamiliares de dois pavimentos e seus lotes 


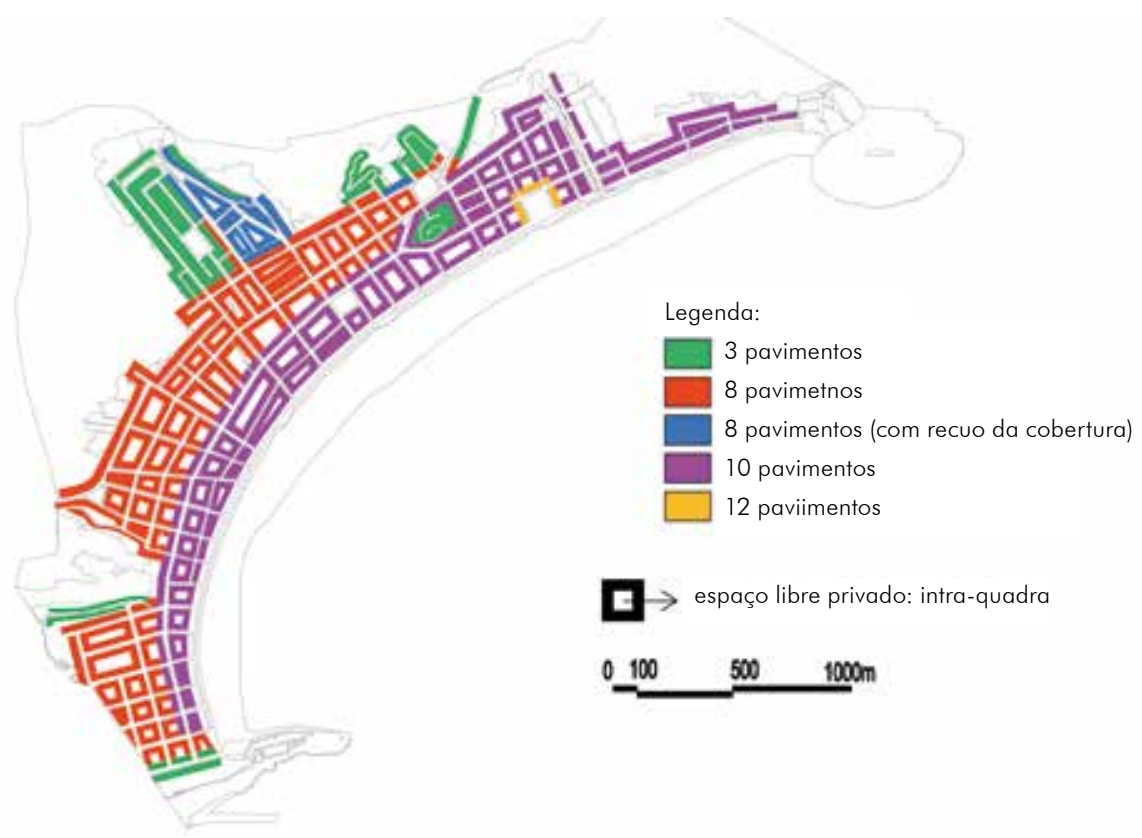

Figura 1: Planta de Zoneamento de 1946, na qual podemos observar as quadras que teriam, a partir daquela data, áreas coletivas intraquadras

Fonte: SEL-RJ, 2009

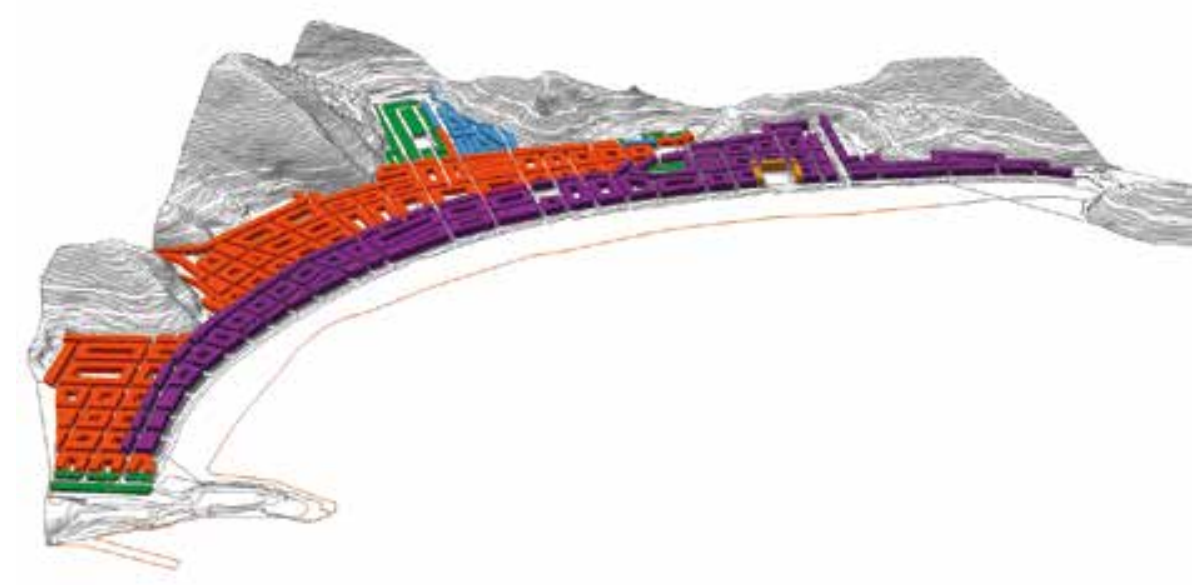

Figura 2: Maquete eletrônica da Planta de Zoneamento de 1946 e a volumetria proposta para todo o bairro

Fonte: SEL-RJ, 2009

apresentavam testadas que variavam de dez a 15 metros em média. Portanto, a proposta das áreas coletivas não alterava a base fundiária de Copacabana. Se tivessem sido propostos lotes com testadas maiores, talvez pudessem dispor de uma melhor qualidade ambiental por meio de novas edificações afastadas das divisas, possibilitando, desse modo, aeração por todas as faces dos edifícios, além de uma maior permeabilidade das quadras. Essa questão, em minha visão, não passava pela cabeça dos urbanistas 
da época, uma vez que o bairro já tinha perdido, desde a década de 1920, a tipologia de edifícios isolados uns dos outros. $O$ alinhamento frontal com edifícios colados às divisas já se configurava como uma marca do bairro.

Outro fato que diz respeito à percepção e apropriação das áreas coletivas é: como já existiam edifícios anteriores à promulgação da legislação que previa espaços livres no interior das quadras, a proposta de obter-se áreas internas ortogonais criando quadras homogêneas não era possível e realmente não aconteceu, pois seria necessário reconstruir-se todas as quadras baseadas nesse novo desenho.

\section{AS ÁREAS COLETIVAS AO LONGO DO TEMPO: USO E APROPRIAÇÃO}

Com a mudança que limitava a profundidade máxima das novas edificações que tinham como característica os embasamentos térreos, os espaços livres resultantes passaram, então, a funcionar como uma área de uso privado das unidades térreas que se voltavam para os fundos, criando-se, assim, quintais de uso diverso e, em sua maioria, descobertos (Figura 3).
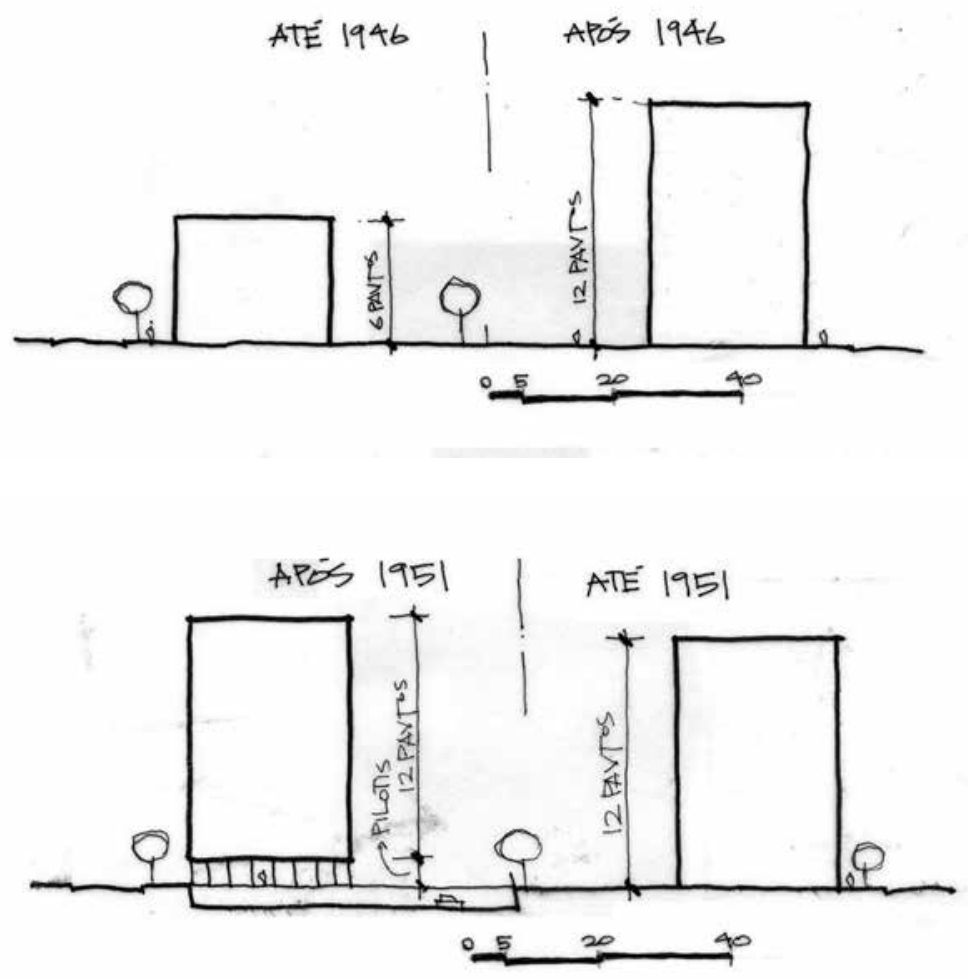

Figura 3: Croqui com o perfil encontrado antes de 1951, quando foi implantado o pilotis Fonte: Autor, 2009
Figura 4: Croqui com o perfil após a implantação do pilotis em 1951

Fonte: Autor, 2009

Poucos anos depois, mais especificamente em 1951, foi introduzido, na cidade, o pilotis no pavimento de acesso, passando, então, o primeiro andar de apartamentos, a ficar localizado acima do térreo (Figura 4). Esses pilotis, em geral, eram parcialmente 
abertos, contendo como partes fechadas somente o hall de acesso e o apartamento do zelador; o restante da área servia, na maioria das vezes, como estacionamento de veículos e áreas de lazer (Figura 5). O pilotis parcialmente aberto não foi adotado em ruas onde era permitida a construção de lojas a ocuparem praticamente toda a testada do lote.

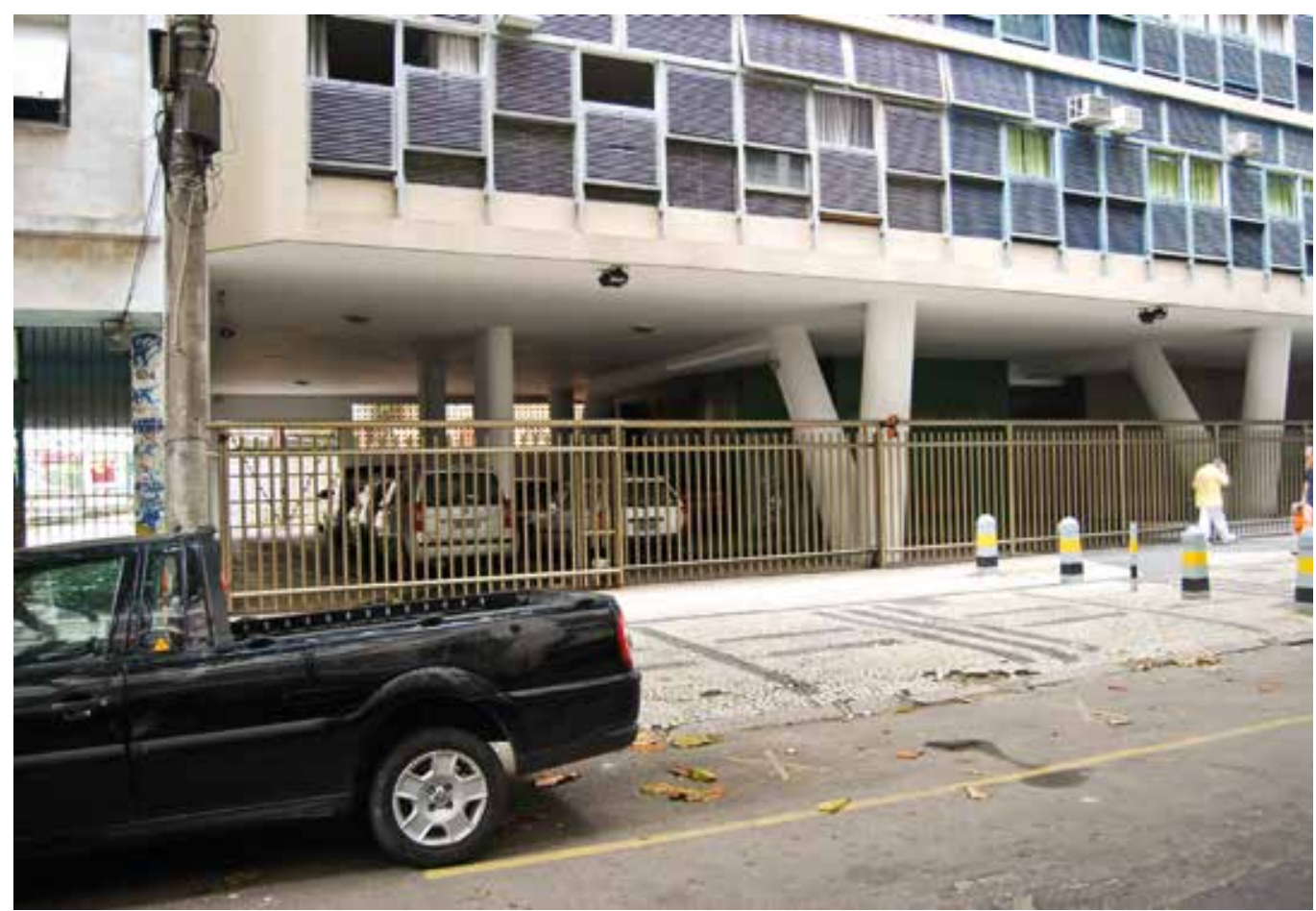

Figura 5: Exemplo de edifício com pilotis; ao fundo, podemos ver os espaços da área coletiva da quadra Fonte: Autor, 2009

Em minha pesquisa esse fato foi objeto de diversas discussões entre pesquisador, orientador e banca examinadora, pois, após diversos debates, pude perceber que esse foi um grande momento para o bairro, pois, com o pilotis aberto, ou pelo menos em parte aberto, esse elemento contribuiu para a melhoria da qualidade ambiental no que diz respeito à circulação de ar, porque possibilitou que essa circulação fosse garantida tanto pela parte superior dos edifícios como pelo nível da rua. Além desse aspecto, a introdução do pilotis também significou a possibilidade de uma maior transição entre o espaço público e o espaço privado, ou seja, entre a rua e o edifício, abrindo o acesso aos espaços livres criados pelas áreas coletivas, de forma a possibilitar uma maior apropriação desses espaços. É importante ressaltar que quando o pilotis foi criado, não eram utilizadas as grades de fechamento na testada dos lotes, o que permitia aos pedestres um caminhar despreocupado e uma maior fluidez entre os pilotis dos edifícios, que se tornava, para as crianças, uma ótima brincadeira.

Já na década de 1970 foi introduzido, na cidade, o embasamento garagem, primeiro com um pavimento e, em 1975, com até quatro pavimentos (Figuras 6 e 7). O pavi- 


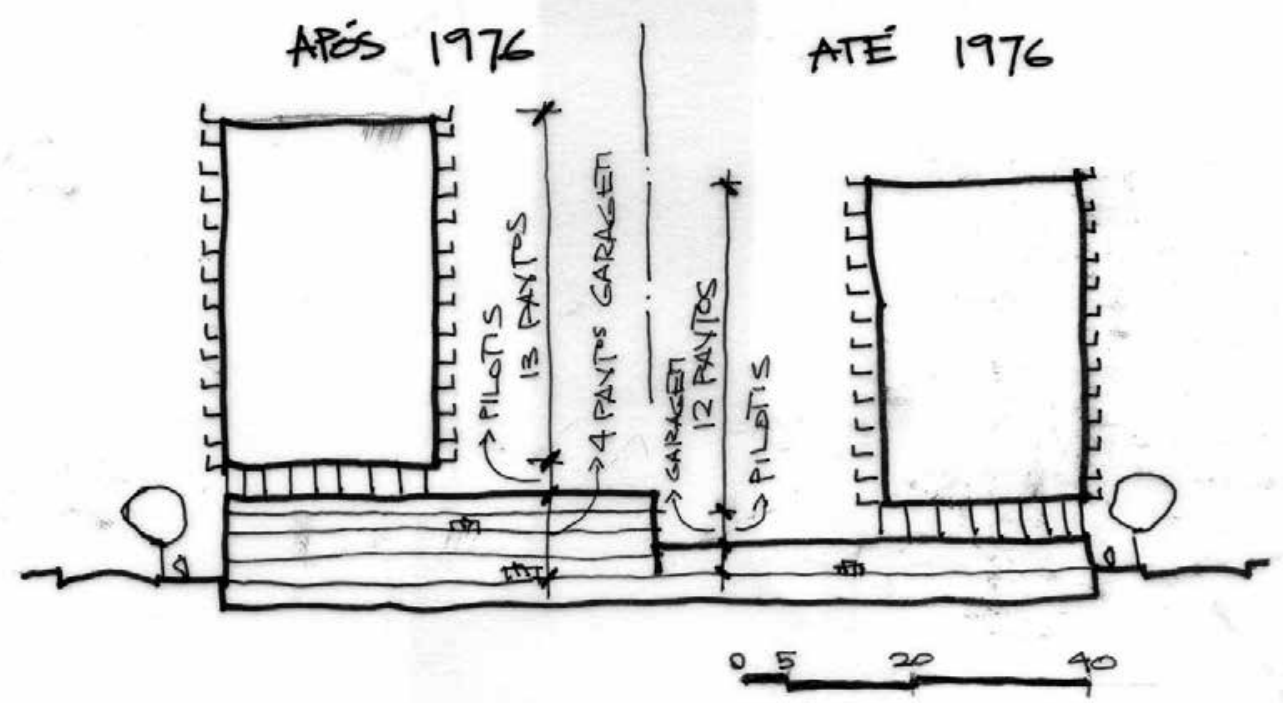

Figura 6: Croqui com o perfil após a implantação do embasamento garagem em 1975 Fonte: Autor, 2009

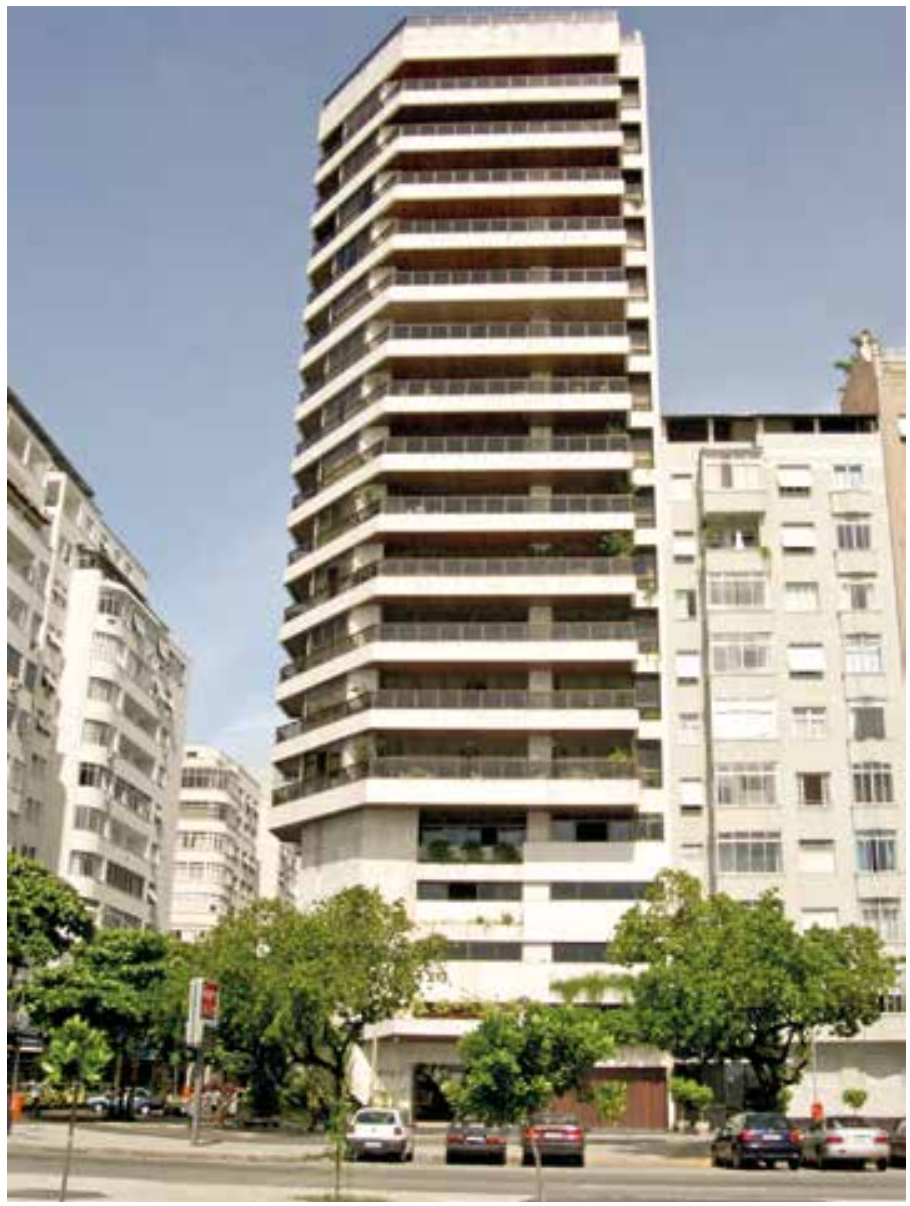

Figura 7: Edifício com o embasamento onde o 7 o andar de apartamentos passa a estar a cinco pavimentos de distância acima do nível da rua Fonte: Autor, 2004 


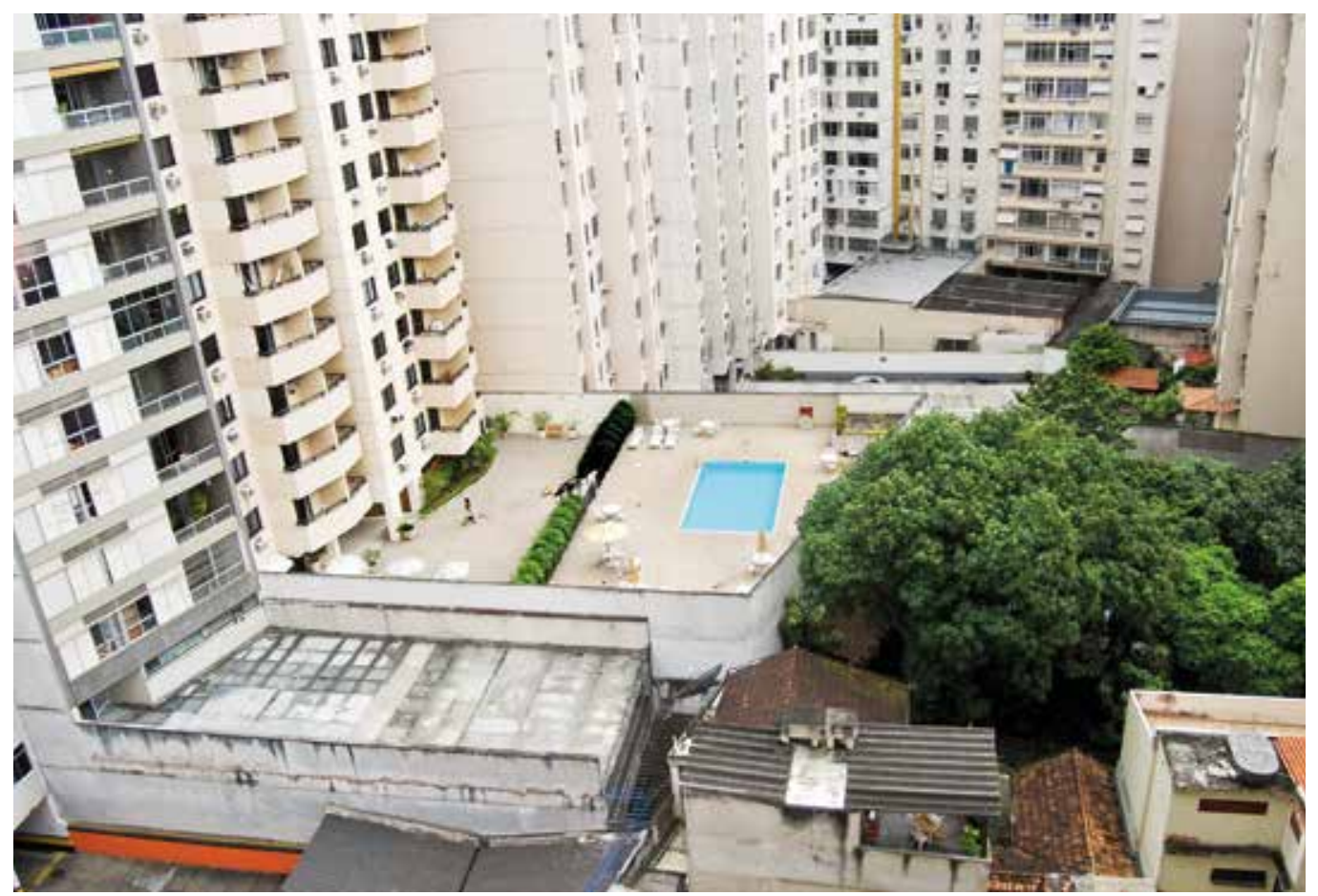

Figura 8: Com a introdução do embasamento, passam a aparecer novos volumes dentro da área coletiva Fonte: Autor, 2004

mento garagem, além de ocupar a totalidade do lote, excluindo o afastamento frontal, poderia avançar para dentro das áreas coletivas, que até então não tinham nenhum tipo de construção permitida. Essa alteração se tornou uma mudança significativa do padrão de espaços livres térreos. Começaram a formarem-se diversos paredões dentro das áreas internas, criando, dessa forma, bloqueios tanto de visibilidade como de circulação de ar (Figura 8).

Outro fator importante que passou a alterar o uso desses espaços livres foi a criação dos pavimentos com estacionamentos cobertos, gerando um movimento, que se estendeu por diversas quadras, de cobrir-se, com estruturas metálicas e telhas de fibrocimento, os espaços livres dentro das áreas coletivas. Os condomínios que até essa época preservavam seus espaços abertos sentiram-se com o direito de também cobri-los, passando a ocorrer uma perda de qualidade desses espaços, pois essas coberturas impedem a circulação do ar e refletem o calor das telhas.

A denominação de área coletiva nunca se efetivou como de tal uso, pelo menos no nível térreo, pois a divisão dos lotes e suas respectivas delimitações por muros não permitiram a criação de um espaço de uso comum, ficando, os moradores, com seus espaços livres restritos a esses limites. $O$ único espaço comum a toda a quadra é o aéreo, no qual os moradores possuem visão de toda a área coletiva, fato o qual, em meu modo de ver, não reduz sua importância de espaço valorizado pelos que residem ou já residiram nessas quadras e têm, conforme constatado nas conversas com moradores, imagens positivas do mesmo. 

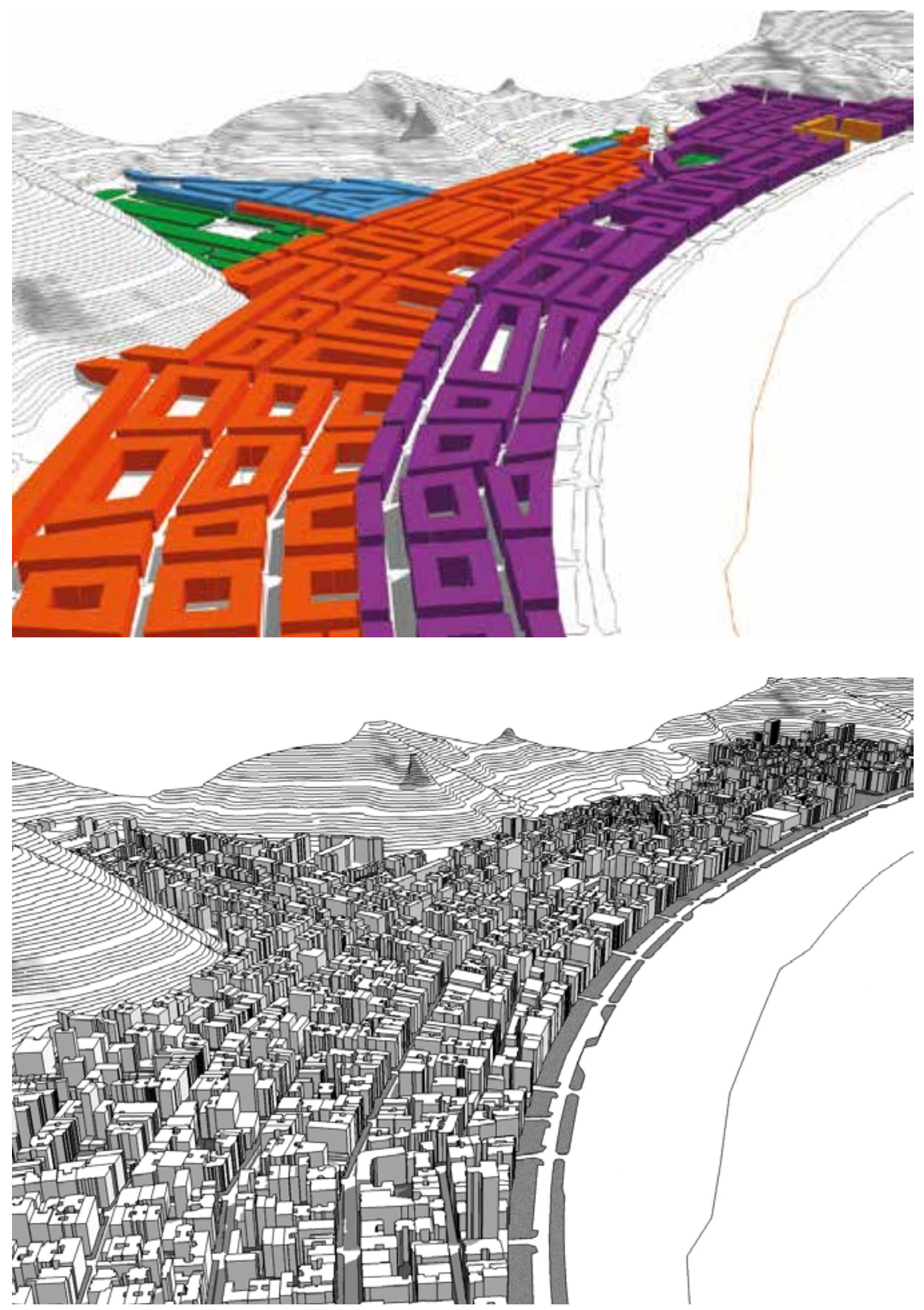

Figuras 9 e 10: Pelas perspectivas panorâmicas da Planta de Zoneamento de 1946 e o perfil encontrado hoje, podemos ver o quanto esse perfil foi alterado ao longo de 54 anos desde sua proposta inicial

Fonte: SEL-RJ, 2010

\section{POR QUE COPACABANA SE DISTINGUE DE OUTROS BAIRROS?}

Apesar de o bairro apresentar, a princípio ou à primeira vista, uma elevada densidade construtiva, existe uma grande quantidade de espaços livres privados, cujo dimensionamento foi comprovado por levantamento e quantificação das densidades líquidas das quadras do bairro. Esses espaços se localizam no interior das quadras, 
configurados pelas áreas coletivas e são pouco apropriadas por grande parte da população que circula pelos espaços públicos do bairro e não entra em contato com essas áreas (Figura 11).

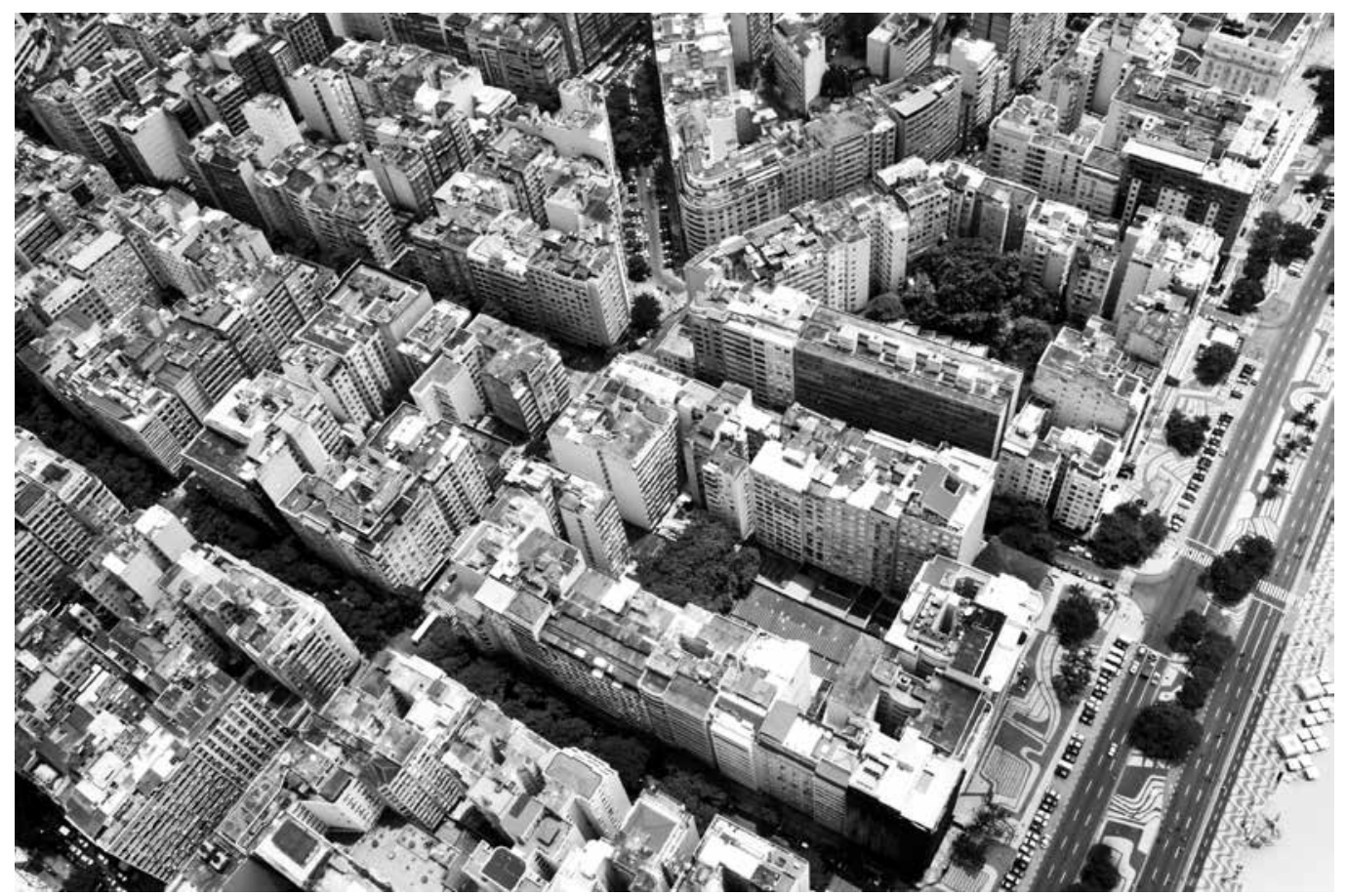

Figura 11: Foto panorâmica das quadras de Copacabana com seus espaços livres intraquadras Fonte: QUAPÁ, 2008

Mesmo com a presença de áreas coletivas em outros bairros, como Catete e Flamengo, em Copacabana essas se apresentam de forma mais significativa em dimensão e quantidade, o que torna essa tipologia de desenho urbano uma característica do bairro. Mesmo não sendo apropriada por muitos e desconhecida como projeto urbano por outros, a incidência dos espaços livres intraquadras qualifica essa paisagem como distinta dentro da cidade do Rio de Janeiro.

Outra situação encontrada no bairro a marcar a relação entre os espaços publico e privado é a grande ruptura existente entre si, não havendo, na maior parte dos casos, uma transição gradual entre os mesmos. Isso acontece pela tipologia dos edifícios, os quais, em sua maioria, têm, em seu pavimento no nível da rua, lojas, portarias e grades que fecham totalmente esse pavimento, não permitindo, assim, que se tenha percepção dos espaços existentes além dessa barreira, inclusive das áreas coletivas no interior das quadras.

\section{CONSIDERAÇÕES FINAIS}

Este artigo pretende divulgar a importância dos espaços livres intraquadras, pouco conhecidos do público em geral e de pesquisadores. As informações obtidas em meu 

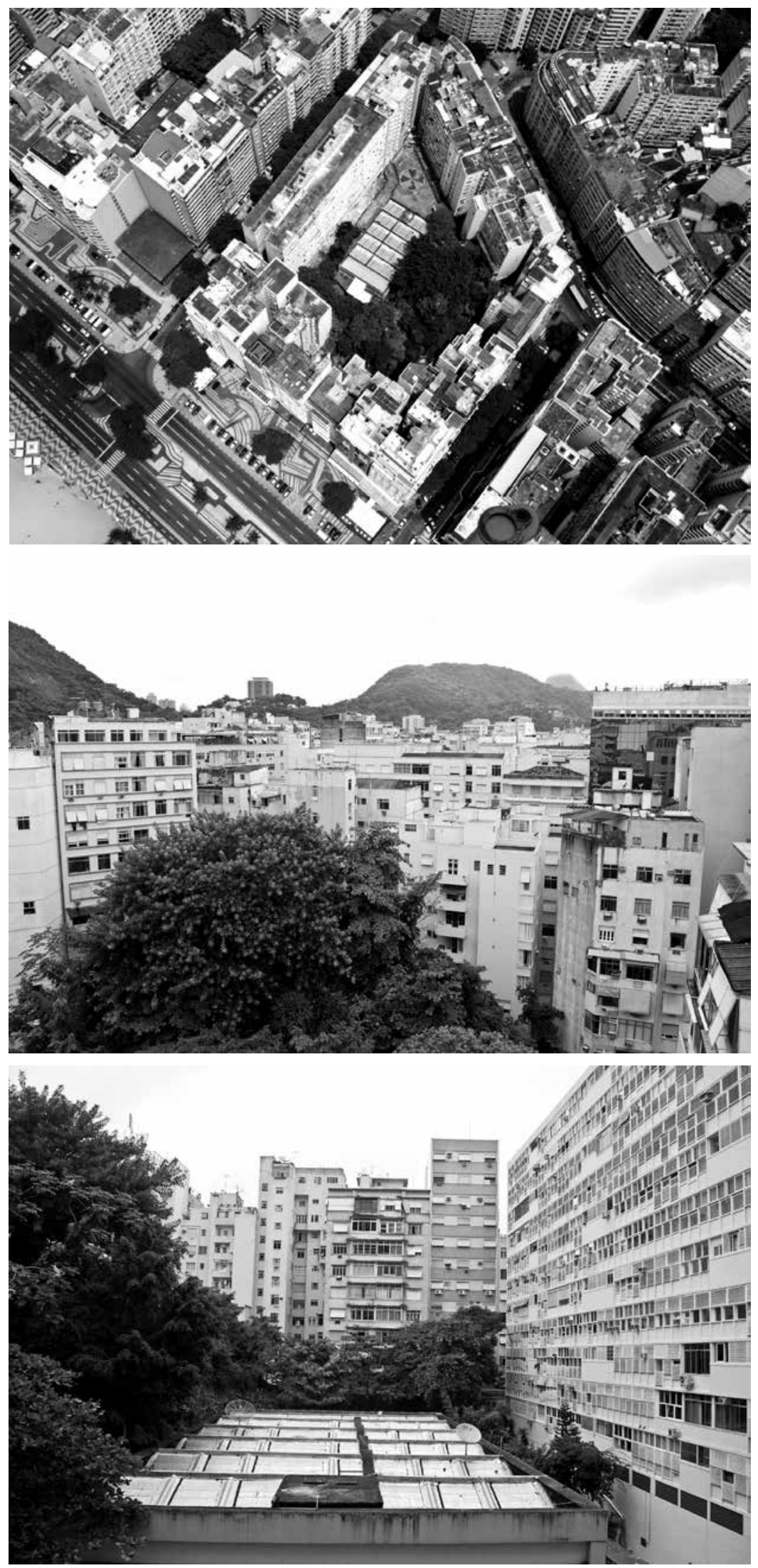

Figuras 12, $13 \mathrm{e}$ 14: Fotos de uma área coletiva de Copacabana. Vista aérea e no nível do edifício, mostrando a sensação do morador perante esse espaço Fonte: QUAPÁ, 2008; autor, 2009 
trabalho poderão fornecer suporte a novos pesquisadores sobre esse perfil de desenho urbano da cidade do Rio de Janeiro. Pretendo, com essa pesquisa, fornecer mais dados que concedam suporte a futuras pesquisas e as comparações, feitas com o bairro de Copacabana, que sejam mais precisas e justas, desmistificando alguns mitos sobre o bairro e consolidando outros. Com certeza ainda existem muitos campos para se pesquisar sobre Copacabana e espero que este estudo seja base para novas pesquisas as quais, futuramente, serão desenvolvidas.

\section{Notas}

(1) Por dentro de Copacabana: Descobrindo os espaços livres do bairro, defendida em fevereiro de 2010 pelo PROARQ-FAU-UFRJ.

\section{Bibliografia}

ABREU, Mauricio de Almeida. A evolução urbana do Rio de Janeiro. Rio de Janeiro: IPP, 2008.

AGACHE, Alfred. Cidade do Rio de Janeiro: Extensão-Remodelação-Embellezamento. Paris: Foyer Brésilien, 1930.

ASHIHARA, Yoshinobu. El diseño de espacios exteriores. Barcelona: Gustavo Gilli, 1981.

CARDEMAN, David; CARDEMAN, Rogério G. O Rio de Janeiro nas alturas. Rio de Janeiro: Mauad, 2004.

CARDEMAN, Rogerio G. Aspectos históricos da construção da paisagem urbana e do sistema de espaços livres do bairro de Copacabana no século XX. Dois séculos de brasilidade: Da transferência da Corte aos países lusófonos e hispânicos. Rio de Janeiro: UFRJ-FAU_PROARQ, 2008.

Por dentro de Copacabana: Descobrindo os espaços livres do bairro. 2010. Dissertação (Mestrado) - Rio de Janeiro: UFRJ-FAU-PROARQ, 2010.

CARDOSO, Elizabeth D. et al. História dos bairros - memória urbana: Copacabana. Rio de Janeiro: João Fortes Engenharia Index, 1986.

LAMAS, José M; GARCIA, Ressano. Morfologia urbana e desenho da cidade. Lisboa: Fundação Calouse Gulbenkian, 2007.

MACEDO, Silvio S. Espaços Livres. Paisagem e Ambiente - Ensaios, São Paulo: FAUUSP, n. 7, 1995.

. Produção da paisagem urbana contemporânea brasileira do final do século 20. Paisagem e Ambiente - Ensaios, São Paulo: FAUUSP, n. 14, 2001.

. Higienópolis e arredores: Processos de mutação de paisagem urbana. São Paulo: Pini/Edusp, 1987.

MAGNOLI, Miranda. Em busca de "outros" espaços livres de edificação. Paisagem e Ambiente - Ensaios, São Paulo: FAUUSP, n. 21, 2006.

. Espaço livre-objeto de trabalho. Paisagem e Ambiente - Ensaios, São Paulo: FAUUSP, n. 21, 2006.

O parque no desenho urbano. Paisagem e Ambiente - Ensaios, São Paulo: FAUUSP, n. 21, 2006.

REIS, José de Oliveira. Censo urbanístico de Copacabana. Rio de Janeiro: Revista Municipal de Engenharia, 1959.

FREIRE, Américo; OLIVEIRA, Lucia Lippi. Novas memórias do urbanismo carioca. Rio de Janeiro: FGV, 2008.

SMU/IPP. Evolução urbanística da cidade do Rio de Janeiro. Rio de Janeiro: IPP, 2008.

Planos urbanos - Rio de Janeiro - século XIX. Rio de Janeiro: IPP, 2008.

TÂNGARI, Vera R. Um outro lado do Rio. 1999. Tese (Doutorado) - Faculdade de Arquitetura e Urbanismo, Universidade de São Paulo, São Paulo, 1999.

VAZ, Lílian Fessler. Modernidade e moradia-habitação coletiva no Rio de Janeiro séculos XIX e XX. Rio de Janeiro: 7letras, 2002. 
